\title{
New developments of thiocarbonyl compounds and sulfines in organic synthesis
}

\author{
Patrick Metzner \\ Laboratoire de Chimie Moléculaire et Thio-organique (Associé au CNRS) \\ ISMRA - Université, 6 boulevard du Maréchal Juin, 14050 Caen, France \\ E-mail : metzner@unicaen.fr
}

\begin{abstract}
The oxidation reaction of aliphatic thiocarbonyl compounds has been revisited in order to give access to the elusive corresponding sulfines and to achieve thiophilic addition of nucleophiles. Various compounds (thioketones, dithioesters, thionesters, trithiocarbonates, trithioperesters) have been treated with a peroxycarboxylic acid. In all cases the corresponding sulfines are formed, in contrast to literature expectations. Their behaviour towards nucleophiles has been investigated. The reaction with alkylithiums proved very useful: a clean and rapid thiophilic addition (no enethiolization) was observed at $-78^{\circ} \mathrm{C}$. The resulting dithioacetal monoxides are easily transformed into carbonyl compounds (aldehydes, ketones) either by a simple mineral acid treatment or by a spontaneous rearrangement which takes place at ambient temperature. It provides a new formal entry to acyl anions (formed by an addition reaction and not by deprotonation). A second illustration of the specific properties of sulfur compounds is disclosed with a new asymmetric version of the Claisen rearrangement. Sulfur is used to facilitate the thermal course of the reaction and a sulfinyl adjacent group is introduced for diastereocontrol First examples show that this transposition indeed occurs at room temperature and with an excellent diastereomeric ratio ( $\geq 93: 7$ ).
\end{abstract}

Sulfur plays a major role in heteroatom chemistry (1). We wish to report our recent results showing more applications to organic synthesis for the specific properties of some sulfur groups. Replacement of the oxygen of a carbonyl group by a sulfinyl group (using a sulfine) allows to reverse the polarity of the $C=S$ moiety and the attack of a nucleophile takes place on sulfur rather than on carbon.
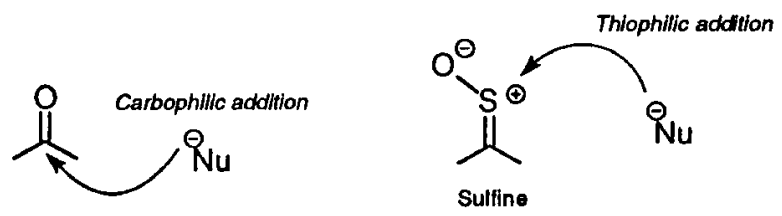

A second part will focus on the replacement of oxygen by sulfur to facilitate a Claisen rearrangement. It is also shown, for the first time, that an auxiliary sulfinyl group can be used efficiently for the diastereocontrol of this [3.3] sigmatropic shift in the acyclic series.

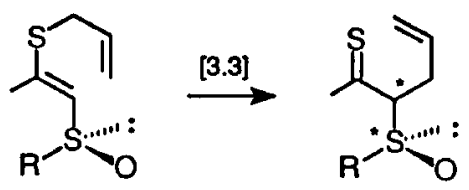

\section{New Sulfines}

Sulfines are attractive heterocumulenes $(2,3)$ whose synthesis and reactivity have been studied with success by Zwanenburg and co-workers, and by the groups of Bonini-Mazzanti (4) and Block (5). Some years ago we embarked on revisiting the oxidation reaction of aliphatic thiocarbonyl compounds (6). For some time we had been puzzled by the literature reports $(2,7,8)$ assuming that enethiolizable thiocarbonyl compounds would not react with oxidizing agents to yield sulfines but would rather lead to divinyl disulfides through oxidation of the tautomeric enethiols. 
In contrast, we have shown that the reaction of meta-chloroperoxybenzoic acid with a variety of thiocarbonyl derivatives, thioketones (tautomerically pure) (9), thionoesters $(10)$, or dithioesters $(11,12)$ quantitatively leads to the thiocarbonyl $\mathrm{S}$-oxides. This reaction (12) is fast at $0^{\circ} \mathrm{C}$ and exhibits a high chemoselectivity $\left(\mathrm{C}=\mathrm{C}, \mathrm{NR}_{2}, \mathrm{C}=\mathrm{O}\right.$ are untouched).

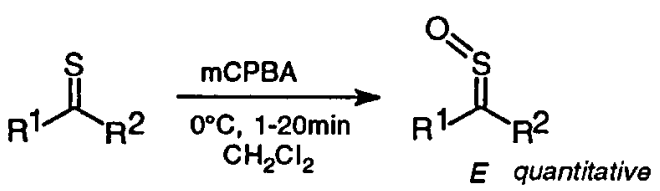

The new aliphatic sulfines are not very stable thermally: for example half lives of sulfines obtained from dithioesters $(11,12)$ are in the range of 2-6 days. They are transformed into dithioperoxyesters, via a new rearrangement $(11,13,14)$. Thus they are available for synthesis provided that they will be used for reactions faster than their transformation. Other classes of thiocarbonyl compounds also lead to sulfines : trithioperesters (14) and trithiocarbonates (15). In the latter case the $\mathrm{S}$-oxides are stable.

During the course of this study we needed to prepare thioketones and their tautomers, enethiols, in the pure isomeric forms. We did achieve the two syntheses (16). Thioketones (devoid of enethiols) were prepared by the reactions of acetals with hydrogen sulfide in the presence of a catalytic amount of $\mathrm{ZnCl}_{2}$ as Lewis acid.

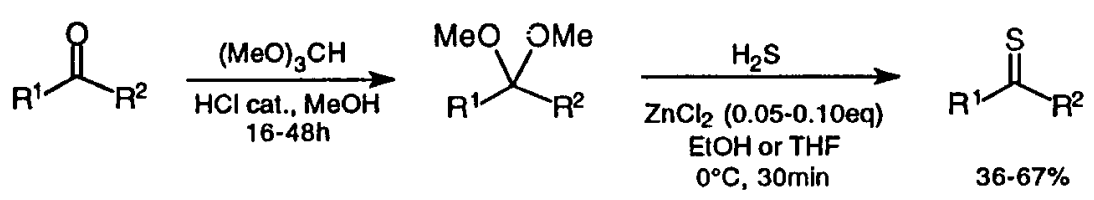

Pure enethiols were obtained (16) by methanol cleavage of silylvinylsulfides, easily available by deprotonation of thioketones and silylation. The very favourable cleavage of the sulfur silicon bond allows to carry out this reaction under such mild conditions that the formed enethiols do not tautomerize to thioketones.

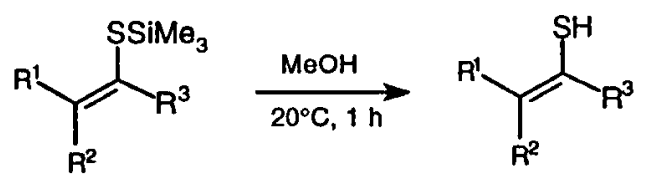

It should also be noted that the first step, deprotonation of thioketones by LDA, occurs to give the cis enethiolates. This stereochemistry is general for thiocarbonyl compounds (17) and it is opposite to that observed with carbonyl compounds (ketones, esters..) in aprotic conditions which lead's to trans enolates. This specific behaviour of sulfur derivatives can be related to their low pKa (for $\mathrm{RCH}_{2} \mathrm{CS}_{2} \mathrm{R}$ $\mathrm{pKa}=11-12$ according to ref. 18) and therefore to a reactant-like transition state. The accompanying scheme shows a ground state conformation with the $\mathrm{R}^{1}$ group eclipsed with the sulfur atom, i.e. a $s$-cis conformation (19) between $C=S$ and $R^{1}$.

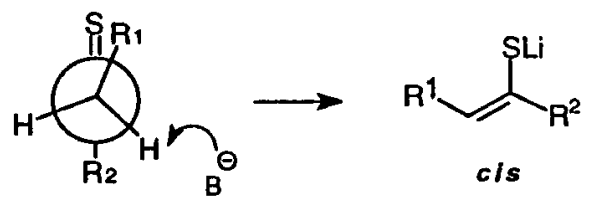




\section{Thiophilic Addition to Sulfines}

Most of the nucleophiles that we have examined so far lead to the attack of sulfur and not of carbon (only exception so far: the reaction of amines - ref 20). In the case of methyllithium a clean and fast reaction is observed at $-78^{\circ} \mathrm{C}$ with sulfines, derived from dithioesters, affording intermediate carbanions, which are stabilized by two sulfur groups. Quenching by various electrophiles $\left(\mathrm{H}_{2} \mathrm{O}, \mathrm{RX}\right.$, enones) quantitatively leads to dithioacetal oxides (21). These masked forms of carbonyl compounds can easily be converted to aldehydes or ketones, by a simple mineral acid treatment $(22,23)$. We discovered that, in many cases, a spontaneous reaction occurs, at room temperature without addition of acid to give the expected carbonyl derivative and a disulfide.

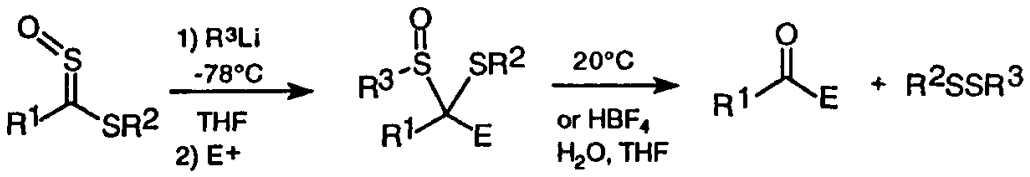

The following mechanism is proposed to explain this reaction, for which some precedents or analogues can be found in the literature (24-26). Rearrangement of the sulfoxide to a sulfenate (27) would be followed by migration of the alkylthio group towards the electrophilic sulfur of the sulfenate.

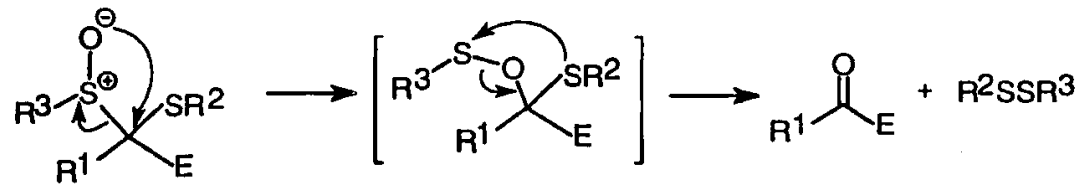

The overall sequence offers a new "Umpolung" entry to aldehydes or ketones. The acyl anion equivalents are formed here by an addition reaction rather than by deprotonation as in the dithiane chemistry $(28,29)$.

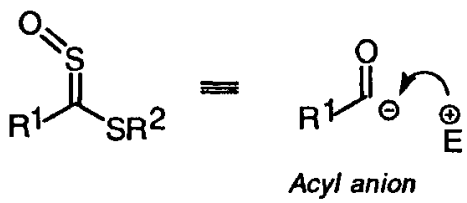

The high reactivity of the sulfinylgroup is highlighted in a new synthesis of cyclopentenones. Reaction of a sulfine bearing a carbonyl group takes place selectively on the sulfur moiety and is followed by an intramolecular addition of the intermediate carbanion to the carbonyl group. The resulting alicyclic dithioacetal oxide undergoes the above rearrangement and elimination of water to provide a cyclopentenone via a one pot procedure (21).<smiles>CC(=O)C(CCC(C)C(C)=O)=S=O</smiles>
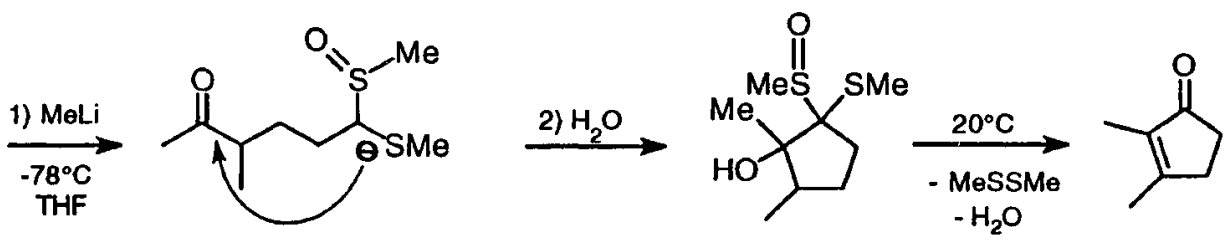

Thiophilic addition of methyllithium to sulfines derived from trithiocarbonates furnishes carbanions which are stabilized by three sulfur groups and therefore are soft nucleophiles. Reaction with enones occurs selectively in a 1,4 orientation (15). The products undergo an easy elimination of methanesulfenic acid to furnish ketenedithioacetals bearing a carbonyl group in the $\beta$ position, derivatives for which very few syntheses are available so far. Silica gel treatment converts these ketenedithioacetals into thiolesters, thus affording a new entry to 1,4-dicarbonyl compounds. 


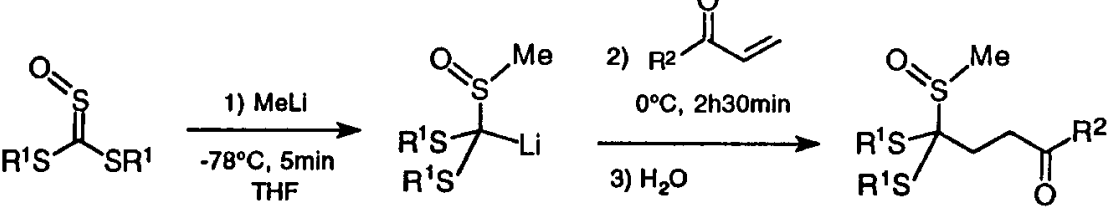

$\mathrm{R}^{1}=\mathrm{Me}, \mathrm{Et}$

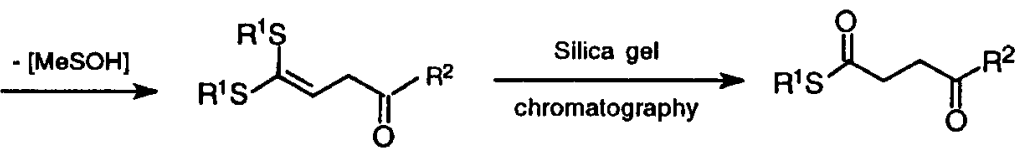

B-oxoketenedithioacetals

$50-70 \%$

\section{Asymmetric Claisen Rearrangement}

We have developed very recently a version of this sigmatropic shift involving two sulfur atoms. First, introduction of one sulfur in the pericyclic nucleus of a Claisen rearrangement substrate facilitates this reaction (17), as reported first by Brandsma (30) and confirmed by the Caen group (31-34). Secondly we have added a chiral sulfinyl group in a position adjacent to the pericyclic nucleus in order to devise a new asymmetric version of the Claisen rearrangement. Though this strategy has been successfully applied to the Diels-Alder cycloaddition (35-38), no analogous [3.3] sigmatropic transposition has been achieved so far (without elimination of a sulfenic acid, see ref 39 ).

We have explored this reaction in the racemic series. Substrates were prepared according to a Claisen condensation of methyl sulfoxides (used by Yokoyama et al, ref 40), by treatment of their carbanions with a trithiocarbonate and subsequent S-allylation of sulfinyl enethiolates. The S-allyl ketenedithioacetals are rearranged at ambient temperature to afford the expected allylated dithioesters. It is noteworthy that the mild conditions prevent the possible elimination of an alkanesulfenic acid. We were delighted to observe an excellent diastereoisomeric ratio ( $\geq 93: 7)$. To the major isomer was assigned the $(S S, 2 S)$ relative configuration by the $\mathrm{X}$-ray crystallographic study of one of the compounds.
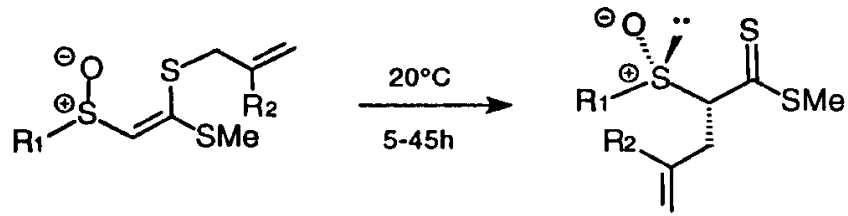

[SS, 2S]

As a tentative model we propose an approach of the electron poor S-allyl moiety on the less hindered face of the electron rich $\mathrm{C}=\mathrm{C}$ bond of the $s$-cis unsaturated sulfoxide.

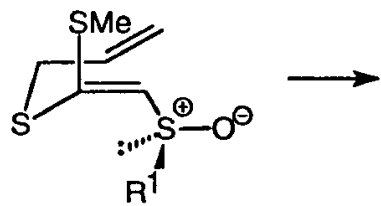

Z, s-trans

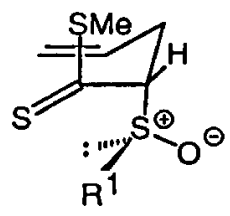

[SS, 2S]

These encouraging preliminary results prompt us to further investigate this rearrangement, with enantiopure substrates and to give access to molecules bearing 3 stereogenic centers.

In conclusion, the reactions that we have developped contribute to the development of thiocarbonyl compounds, for a long time considered as rather exotic species. They are now versatile tools for the creation of $\mathrm{C}-\mathrm{C}$ bonds (17). 
Acknowledgments. I wish to thank warmly the dedicated chemists who achieved this challenging work: Carole Alayrac, Francesca Cerreta, Isabelle Chapron, Florence Corbin, Christophe Fromont, Bruno Lelong, Anne-Marie Le Nocher, Catherine Leriverend and Pham Thi Nhàn.

\section{References}

1. P. Metzner and A. Thuillier, Sulfur Reagents in Organic Synthesis (Academic Press, Londres, 1994).

2. B. Zwanenburg, Recl. Trav. Chim. Pays-Bas, 101, 1 (1982).

3. B. Zwanenburg, Phosphorus, Sulfur Silicon Relat. Elem., 43, 1 (1989).

4. B. F. Bonini, Phosphorus, Sulfur Silicon Relat. Elem., 74, 31 (1993).

5. E. Block, Angew. Chem., Int. Ed. Engl., 31, 1135 (1992).

6. P. Metzner, Phosphorus, Sulfur Silicon Relat. Elem., 59, 1 (1991).

7. M. van der Leij and B. Zwanenburg, Tetrahedron Lett., 3383 (1978).

8. P. A. T. W. Porskamp, M. van der Leij, B. H. M. Lammerink, and B. Zwanenburg, Recl. Trav. Chim. Pays-Bas, 102, 400 (1983).

9. A.-M. Le Nocher and P. Metzner, Tetrahedron Lett., 32, 747 (1991).

10. M. Lemarié, P. Metzner, and T. N. Pham, Tetrahedron Lett., 32, 7411 (1991).

11. P. Metzner and T. N. Pham, J. Chem. Soc., Chem. Commun., 390 (1988).

12. F. Cerreta, A.-M. Le Nocher, C. Leriverend, P. Metzner, and T. N. Pham, Bull. Soc. Chim. Fr., 132, 67 (1995).

13. J. B. van der Linden, J. L. Timmermans, and B. Zwanenburg, Recl. Trav. Chim. Pays-Bas, 114, 91 (1995).

14. C. Leriverend and P. Metzner, Tetrahedron Lett., 35, 5229 (1994).

15. A. Capperucci, A. Degl'Innocenti, C. Leriverend, and P. Metzner, to be published.

16. A.-M. Le Nocher and P. Metzner, Tetrahedron Lett., 33, 6151 (1992).

17. P. Metzner, Synthesis, 1185 (1992).

18. A. C. Storer, Can. J. Chem., 61, 1440 (1982).

19. P. Beslin and Y. Vallee, Tetrahedron, 41, 2691 (1985).

20. F. Cerreta, C. Leriverend, and P. Metzner, Tetrahedron Lett., 34, 6741 (1993).

21. C. Alayrac, F. Cerreta, F. Corbin, I. Chapron, and P. Metzner, to be published.

22. R. Kuhn and F. A. Neugaber, Chem. Ber., 94, 2629 (1961).

23. K. Ogura, Pure Appl. Chem., 59, 1033 (1987).

24. Y. Kishi, T. Fukuyama, and S. Nakatsuka, J. Am. Chem. Soc., 95, 6490 (1973).

25. C. Huynh and S. Julia, Synth. Commun., 7, 103 (1977).

26. A. Ishii, T. Akazawa, T. Maruta, J. Nakayama, M. Hoshino, and M. Shiro, Angew. Chem., Int. Ed. Engl., 33, 777 (1994).

27. T. J. Maricich and C. K. Harrington, J. Am. Chem. Soc., 94, 5115 (1972).

28. K. Ogura, in Studies in Natural Products Chemistry - Stereoselective Synthesis, edited by A.-U. Rahman (Elsevier, Amsterdam, 1990), Vol. 6, Part D, p. 307. 
29. K. Ogura, in Comprehensive Organic Synthesis, edited by B. M. Trost, I. Fleming and S. L. Schreiber (Pergamon Press, Oxford, 1991), Vol. 1, p. 505.

30. L. Brandsma, Recl. Trav. Chim. Pays-Bas, 89, 596 (1970).

31. P. Metzner, T. N. Pham, and J. Vialle, Nouv. J. Chim., 2, 179 (1978).

32. S. Désert, P. Metzner, and M. Ramdani, Tetrahedron, 48, 10315 (1992).

33. P. Beslin and S. Perrio, Tetrahedron, 47, 6275 (1991).

34. P. Beslin and S. Perrio, Tetrahedron, 48, 4135 (1992).

35. T. Koizumi, Phosphorus, Sulfur Silicon Relat. Elem., 58, 111 (1991).

36. C. Maignan, A. Guessous, and F. Rouessac, Tetrahedron Lett., 25, 1727 (1984).

37. B. Ronan and H. B. Kagan, Tetrahedron: Asymmetry, 2, 75 (1991).

38. I. Alonso, J. C. Carretero, and J. L. Garcia Ruano, J. Org. Chem., 59, 1499 (1994).

39. G. H. Posner, R. D. Crouch, C. M. Kinter, and J.-C. Carry, J. Org. Chem., 56, 6981 (1991).

40. M. Yokoyama, K. Tsuji, M. Hayashi, and T. Imamoto, J. Chem. Soc., Perkin Trans. 1, 85 (1984). 